\title{
CULTURA POLÍTICA E INSTITUIÇÕES NO BRASIL REGENCIAL: A PRIMEIRA LEGISLATURA DA ASSEMBLEIA PROVINCIAL DE PERNAMBUCO (1835-1836)
}

\author{
CULTURA POLÍTICA E INSTITUCIONES EN BRASIL REGENCIAL: LA \\ PRIMERA LEGISLATURA DE LA ASAMBLEA PROVINCIAL DE \\ PERNAMBUCO (1835-1836)
}

Manoel Nunes Cavalcanti Junior

Instituto Federal da Bahia - IFBA

\begin{abstract}
Resumo
Em seus primeiros anos, o governo regencial do Brasil Império tomou uma série de medidas políticas e administrativas de caráter descentralizador, buscando amenizar a centralização que caracterizou o período anterior do Primeiro Reinado. Um dos símbolos destas mudanças foi a instituição das Assembleias Provinciais, criada pela reforma constitucional do Ato Adicional de 1834. O objetivo era conceder maior autonomia às províncias no âmbito de sua administração. Este trabalho tem por finalidade principal analisar a implantação na província de Pernambuco de sua Assembleia, desde a forma de escolha dos primeiros deputados até o funcionamento de sua primeira legislatura. Com as ferramentas da história política e dos estudos de cultura política, busca-se entender a maneira como esta nova instituição se incorporou às políticas locais, as ligações dos seus deputados com as diferentes facções que lutavam pelo poder na província e seu papel nas mudanças que aconteciam na Regência.
\end{abstract}

Palavras-chave: Brasil Império. Regência. Cultura Política.

\section{Resumen}

En sus primeros años, el gobierno de regencia de Brasil Império tomó una serie de medidas políticas y administrativas de carácter descentralizador, buscando 


\section{LEGISLATURA DA ASSEMBLEIA PROVINCIAL DE PERNAMBUCO (1835-1836)}

suavizar la centralización que caracterizó el período anterior del Primer Reinado. Uno de los símbolos de estos cambios fue la institución de las Asambleas Provinciales, creada por la reforma constitucional de la Ley Adicional de 1834. El objetivo era otorgar una mayor autonomía a las provincias en el ámbito de su administración. Este trabajo tiene como objetivo principal analizar la implantación en la provincia de Pernambuco de su Asamblea, desde la forma de elegir a los primeros diputados hasta el funcionamiento de su primera legislatura. Con las herramientas de la historia política y los estudios de cultura política, buscamos comprender la forma en que esta nueva institución se incorporó a la política local, las conexiones de sus diputados con las diferentes facciones que lucharon por el poder en la provincia y su papel en los cambios que sucedió en la regencia.

Palabras clave: Imperio de Brasil. Regencia. Cultura Política.

O período regencial da história do Brasil Império, que se estendeu de 1831 a 1840, é um dos mais instigantes de nossa história política. Caracterizou-se por acirradas disputas e embates entre elites locais por todo o seu território. Nos seus nove anos de duração praticamente todas as províncias tiveram experiências de lutas intestinas, levantes, manifestações de rua, motins e distúrbios os mais diversos. As paixões suscitadas resultaram em análises divergentes sobre o seu legado e sua natureza. Ainda no séc. XIX os conservadores enfatizaram a sua instabilidade, a desordem e a insubordinação daqueles anos. Já os liberais preferiram chamar a atenção para o que denominaram de triunfo da liberdade. Segundo Marcello Basile, a primeira perspectiva acabou preponderando na historiografia posterior, atraindo maior simpatia pela ação dos moderados e críticas a um pretenso radicalismo dos exaltados e restauradores (BASILE, 2009, p. 55-61).

No entanto, novas abordagens abriram caminho para se enxergar a Regência como uma espécie de "laboratório da Nação", nas palavras ainda de Basile. Voltava-se ao debate de uma questão que, segundo José Murilo de Carvalho, era uma constante na história do Brasil: a dicotomia entre centralização e descentralização. No caso específico da Regência, a descentralização predominou sobre a centralização do $1^{\circ}$ Reinado. Os poderes localistas saíram vitoriosos com a abdicação de Pedro I, chegando-se a ter em voga uma proposta de Revista RBBA Revista Binacional Brasil Argentina 

LEGISLATURA DA ASSEMBLEIA PROVINCIAL DE PERNAMBUCO (1835-1836)

Monarquia Federalista que não foi adiante, mas deu o caráter descentralizador ao Ato Adicional de 1834 (CARVALHO, 2005, p. 164-167). Para Miriam Dolhnikoff, a discussão sobre descentralização e federalismo no início da Regência levou os liberais a implantarem uma série de reformas que promoveram um novo arranjo institucional para a Nação, com maior espaço de atuação para as províncias e o surgimento nelas de uma elite que intermediaria as relações entre os poderes locais e a corte (DOLHNIKOFF, 2005). Tais reformas começaram ainda em 1831, com a criação da Guarda Nacional, passaram pela elaboração do Código de Processo de 1832 e culminaram com a reforma constitucional levada a cabo pelo Ato Adicional de 1834 .

Neste trabalho nos concentraremos em analisar a implantação de um dos símbolos das medidas descentralizadoras do período: as assembleias provinciais. Mais especificamente a implantação desta nova instituição na província de Pernambuco. A preocupação é entender a maneira como a Assembleia se incorporou às lutas entre facções locais pelo poder na província e o seu papel na formulação de caminhos para o momento de transformações pelo qual passava a Regência.

\section{0 surgimento das Assembleias}

A instituição que antecedeu as Assembleias Provinciais foi o Conselho Geral. Criado pela Constituição de 1824, havia uma em cada província. Nas maiores, como era o caso de Pernambuco, seria formado por vinte e um membros, enquanto nas menores este número seria de treze. Os conselheiros seriam escolhidos por meio de eleição, da mesma forma como eram eleitos os deputados gerais, e teriam um mandato de quatro anos. Segundo o texto constitucional, o principal objetivo deste Conselho propor, discutir e deliberar sobre assuntos de interesse da província. No entanto, suas limitações eram muitas. O Conselho não poderia deliberar sobre assuntos gerais do império e que diziam respeito às atribuições da Câmara dos Deputados. Além disso, não poderia criar qualquer lei, se limitando, nestes casos, a enviar à Câmara na corte uma representação solicitando a análise da questão. ${ }^{\mathrm{i}}$ Em resumo, os Conselhos Gerais de Província estavam enquadrados na centralização político-administrativa que caracterizou o $1^{\mathrm{o}}$ Reinado.

O Ato Adicional de 1834 modificou este cenário ao extinguir os Conselhos Gerais e criar as Assembleias Provinciais. Segundo Miriam Dolhnikoff, elas resultaram da vitória do projeto político liberal que previa a autonomia provincial e a unidade do território sob a

\begin{tabular}{l|l} 
Revista RBBA & Revista Binacional Brasil Argentina
\end{tabular} 
CULTURA POLÍTICA E INSTITUIÇÕES NO BRASIL REGENCIAL: A PRIMEIRA

\section{LEGISLATURA DA ASSEMBLEIA PROVINCIAL DE PERNAMBUCO (1835-1836)}

direção do Rio de Janeiro. Os liberais moderados propunham a distribuição equilibrada do aparelho de Estado pelo território como sendo um projeto nacional capaz de articular as diversas elites provinciais e inseri-las no jogo do poder imperial. No intuito de controlar as elites locais, historicamente desestabilizadoras, fomentou-se a criação e fortalecimento das elites provinciais, submetendo aquelas a estas (DOLHNIKOFF, 2005, p. 81-83).

Dentre as atribuições dadas pela reforma constitucional às novas Assembleias, a autora destaca algumas (DOLHNIKOFF, 2005, p. 156-204). Primeiro, a competência tributária. O Ato Adicional deu autonomia às províncias para a elaboração do orçamento provincial. Caberia agora exclusivamente às Assembleias Provinciais a responsabilidade sobre este assunto. Isto dividiu a competência tributária entre as províncias e o governo central, cuja única possibilidade de interferência seria através do veto presidencial, mas que poderia ser derrubado com $2 / 3$ dos votos dos deputados provinciais. Os impostos que passariam a ser provinciais eram impostos já existentes, antes arrecadados pelo governo central. Normalmente seriam aqueles que taxavam atividades internas, de difícil cobrança por parte do Rio de Janeiro devido aos obstáculos de atingir todo o território. Com isso, essa autonomia tributária iria facilitar o trabalho, pois as províncias estariam mais aparelhadas para alcançar localidades muito distantes da Corte.

Em segundo lugar, as obras públicas. Com a autonomia tributária, os governos provinciais puderam desenvolver uma política econômica voltada para o desenvolvimento material de suas províncias. São Paulo, Pernambuco e Rio Grande do Sul se empenharam, particularmente, na ampliação e modernização das suas vias de transporte, a fim de melhorar o escoamento da produção. Pontes e estradas significavam aumento do comércio provincial e o incremento das rendas públicas, garantindo assim o retorno do investimento. Em Pernambuco, boa parte do seu orçamento se destinava a estradas e pontes, assim como a compra de máquinas e de tecnologia para incrementar a produção do açúcar e torná-lo mais competitivo no mercado externo. O esforço em beneficiar a principal atividade econômica da província era utilizado como instrumento de poder político, pois agia no sentido da conquista do apoio dos grandes proprietários. Algumas províncias criaram órgãos responsáveis pelo planejamento, execução e fiscalização das obras públicas. Pernambuco, por exemplo, criou a Administração Geral das Obras Públicas. 

LEGISLATURA DA ASSEMBLEIA PROVINCIAL DE PERNAMBUCO (1835-1836)

Em seguida vem o controle das Assembleias sobre os empregos provinciais e a força policial. O Ato Adicional deu a prerrogativa às Assembleias Legislativas de criar, extinguir e modificar os empregos provinciais e municipais. Tal poder, naquele contexto, era crucial no jogo do clientelismo político para cooptação de grupos locais. Os deputados possuíam grande poder de favorecimento dos seus apadrinhados, sendo até maior do que o presidente da província. A força policial era parte do corpo de empregados provinciais. Sua organização e sustento ficavam a cargo da Assembleia. Esta força tinha duas atribuições importantes: era responsável pela manutenção interna cotidiana, enquanto a Guarda Nacional era utilizada na repressão a movimentos maiores, como rebeliões; e garantir a cobrança de tributos.

Por fim, destaca-se a dependência com que os municípios ficaram em relação às Assembleias Provinciais. As Câmaras Municipais recorriam ao governo provincial para satisfazer praticamente a todas suas necessidades financeiras. Elas, por exemplo, não podiam contratar nenhum funcionário se não fosse autorizada pela Assembleia, além de seus salários também serem definidos pelos deputados. Os deputados se viam como uma elite letrada, responsável por encaminhar as elites locais nos trilhos do Estado moderno. Enxergavam sua missão como sendo civilizatória. As elites provinciais usavam a Assembleia como instrumento no controle e disciplinamento destas elites locais, esvaziando aos poucos os poderes das Câmaras. Esta perspectiva era compartilhada tanto por liberais como por conservadores, pois a situação permanecerá a mesma depois da Regência, percorrendo todo o Império e chegando até a República.

\section{A primeira eleição para deputados provinciais}

Para Pernambuco, assim como Bahia, Rio de Janeiro, Minas e São Paulo, seriam eleitos trinta e seis deputados provinciais. A eleição destes deputados seria semelhante à dos deputados gerais, sendo escolhidos pelos respectivos eleitores. Cada legislatura duraria dois anos. ${ }^{\text {ii }}$

Como determinava a lei, a eleição deveria acontecer imediatamente à sua promulgação. Os eleitores daquela legislatura (1834 - 1837) se reuniriam em seus respectivos colégios para depositarem as suas listas. Em Pernambuco ela foi marcada para o dia 30 de novembro de 1834. Segundo o edital da Câmara Municipal do Recife, os eleitores da capital deveriam comparecer à Igreja de São Pedro, ficando a apuração marcada para o dia 25 de janeiro do ano seguinte. ${ }^{\text {iii }}$

\begin{tabular}{l|l} 
Revista RBBA & Revista Binacional Brasil Argentina
\end{tabular} 
CULTURA POLÍTICA E INSTITUIÇÕES NO BRASIL REGENCIAL: A PRIMEIRA

\section{LEGISLATURA DA ASSEMBLEIA PROVINCIAL DE PERNAMBUCO (1835-1836)}

A se tomar como medida o que foi divulgado nos jornais, a campanha eleitoral foi morna. Muito pouco se disse sobre o processo. O Diário de Pernambuco chegou a fazer uma defesa do perfil ideal dos futuros deputados provinciais. Segundo o jornal, as pessoas a serem escolhidas para compor a Assembleia Provincial deveriam ser boas, instruídas, verdadeiramente interessadas no bem-estar do povo. Teriam que possuir muita probidade, sincero apego "à nossa santa causa e instituições livres". Defendia ainda que as diferentes classes fossem representadas: homens de letras, negociantes, lavradores, fabricantes e militares. Além destes, deveriam existir representantes do interior. Sobre este ponto afirmava que não se podia negar o egoísmo dos habitantes do litoral em relação aos do interior, estando o centro da província abandonado e em total ignorância. Em um comunicado, alguém demonstrava preocupação com a opinião de eleitores do interior: alguns andavam dizendo que apenas os proprietários e os agricultores mereciam ser votados. O autor chamava a atenção para o fato de que os trabalhos do Conselho do Governo eram prejudicados justamente por conta da presença de senhores de engenho que, não querendo abandonar seus negócios em tempo de plantação ou colheita, faltavam muito e inviabilizavam seus trabalhos. ${ }^{\text {iv }}$ Para o correspondente $O$ Pernambucano, os futuros deputados tinham que ser pernambucanos natos, pois era necessário que amassem a província e a conhecessem. Daí defender que pessoas de outras províncias não podiam ser eleitas, pois eram como que estrangeiras. ${ }^{\mathrm{v}}$

Não há relatos de problemas durante o transcorrer do dia da eleição, mesmo estando em meio à crise da relação entre o então presidente da província, Manoel de Carvalho Paes de Andrade, e o grupo dos liberais exaltados locais. ${ }^{\text {vi }}$ Dois dias depois, em 2 de dezembro, estouraria o primeiro embate, com a tentativa de mobilização da Guarda Nacional pelos irmãos Machado Rios durante a parada militar em homenagem ao aniversário de Pedro II. ${ }^{\text {vii }}$

Houve denúncia, por parte dos adversários do governo provincial, de que Manoel de Carvalho havia tentado cooptar eleitores. O correspondente de um jornal da oposição chegou a afirmar: "Qual foi a casa desta Cidade (Recife), onde se não leram as cartas de favor, e as listas, que se espalharam, por ocasião de se elegerem os Deputados de província?". viii Mesmo com a negativa dos liberais moderados locais, apoiadores do presidente, é difícil imaginar que o governo não tenha se mobilizado para tentar eleger aliados. De sua parte, os governistas também acusaram a oposição no aliciamento de eleitores. Um correspondente do periódico $\mathrm{O}$ Velho Pernambucano afirmou: "De outro lado comprometemo-nos a provar que o Sr. Antônio 

LEGISLATURA DA ASSEMBLEIA PROVINCIAL DE PERNAMBUCO (1835-1836)

Carneiro Machado Rios abandonou o ponto de baixo do seu comando, e veio a Santo Antão pedir - propria persnona - votos para si, e outros muitos que de certo oferecem grandes garantias..."ix Segundo o periódico moderado, estas pessoas seriam o tenente coronel Francisco Carneiro Machado Rios, o tenente João Ribeiro Pessoa de Lacerda e João Manoel Mendes da Cunha e Azevedo.

O primeiro resultado parcial da eleição foi dado pelo Diário de Pernambuco já no dia 2 de janeiro de 1835. À medida que iam chegando as listas do interior, outras parciais eram dadas, como as dos dias 10 e 16 do mesmo mês. Somente no dia 26 de fevereiro foi que o Diário publicou a lista definitiva, a partir da apuração realizada pela Câmara Municipal da capital.

A maior surpresa na relação dos eleitos foi a inclusão do nome do juiz de direito e chefe de polícia do Recife, Joaquim Nunes Machado. Seu nome não constava nas listas parciais divulgadas no mês de janeiro. Isso levou um correspondente do Diário de Pernambuco, $O$ Imparcial, a tocar no assunto. Em uma primeira correspondência ele citou boatos de que a apuração da Câmara Municipal do Recife fora inexata, chegando alguns a dizerem que houve conluio e influência chimanga (liberais moderados). Dizia o correspondente que os vereadores foram pouco escrupulosos, se fundamentando em duas razões. Primeiro, eles utilizaram pretextos para colocar de lado os votos de pessoas que lhes desagradavam, possuidoras de convicções firmes e coragem para dizer a verdade na Assembleia. Segundo, que o nome de Nunes Machado aparecia entre os trinta e seis eleitos, quando particulares, em suas apurações, mostraram que ele nem entre os suplentes estava. Mesmo que estes particulares não contassem com um ou dois colégios, o total de votos destes colégios não era suficiente para modificar a situação de Nunes Machado. Ele achava que foi apenas descuido dos vereadores e uma nova apuração deveria corrigir os erros. Em outra correspondência, o mesmo $O$ Imparcial reverberou a opinião de muitos que afirmavam ter havido conluio da própria Câmara Municipal do Recife e influência chimanga para beneficiar alguns candidatos. Ele esperava que os vereadores recontassem os votos para dirimir quaisquer dúvidas. ${ }^{\mathrm{x}}$

A polêmica levou a Câmara a agir. Na sessão do dia 5 de março o presidente, vereador Francisco Antônio de Oliveira, propôs repetir a apuração dos votos, visto as acusações publicadas em jornais de viciosa ou pouco escrupulosa dadas à primeira. Isto suscitou um debate, com uns vereadores falando contra e outros a favor. No final, todos foram favoráveis,

\begin{tabular}{l|l} 
Revista RBBA & Revista Binacional Brasil Argentina
\end{tabular} 


\section{LEGISLATURA DA ASSEMBLEIA PROVINCIAL DE PERNAMBUCO (1835-1836)}

com exceção do Dr. Mavignier, cujo voto foi feito por escrito. Realizada a recontagem, percebeu-se que Joaquim Nunes Machado recebera apenas 104 votos, e não 148 como havia sido contado na apuração anterior. Para o seu lugar na Assembleia deveria ser chamado o Dr. José Eustáquio Gomes, $1^{\mathrm{o}}$ suplente. ${ }^{\mathrm{xi}}$ Fechava-se, assim, a composição da Assembleia Provincial de Pernambuco para a sua primeira legislatura, conforme podemos ver no Quadro 1.

QUADRO 01 - Lista dos Deputados Provinciais para a $1^{\mathrm{a}}$ Legislatura (1835-1836) da Assembleia Provincial de Pernambuco. ${ }^{\text {xii }}$

\begin{tabular}{|c|c|c|}
\hline & NOME & $\mathbf{N}^{\circ}$ DE VOTOS \\
\hline 1 & Pe. Miguel do Sacramento Lopes Gama & 531 \\
\hline 2 & Dr. Pedro Francisco de Paula Cavalcanti de Albuquerque & 375 \\
\hline 3 & Francisco de Paula Cavalcanti de Albuquerque & 334 \\
\hline 4 & Pe. Francisco José Correia & 298 \\
\hline 5 & Tiburtino Pinto de Almeida & 292 \\
\hline 6 & Pe. Luiz Carlos Coelho da Silva & 269 \\
\hline 7 & Firmino Herculano de Moraes Ancora & 254 \\
\hline 8 & Pe. Laurentino Antônio Moreira de Carvalho & 250 \\
\hline 9 & Gervázio Pires Ferreira & 236 \\
\hline 10 & Pe. Virgínio Rodrigues Campelo & 233 \\
\hline 11 & Manoel Zeferino dos Santos & 226 \\
\hline 12 & José Ramos de Oliveira & 220 \\
\hline 13 & Pe. Joaquim Rafael & 217 \\
\hline 14 & Thomaz Antônio Maciel Monteiro & 214 \\
\hline 15 & Antônio Carneiro Machado Rios & 207 \\
\hline 16 & Joaquim Francisco de Mello Cavalcanti & 207 \\
\hline 17 & Leonardo Bezerra de Siqueira Cavalcanti & 207 \\
\hline 18 & Nicolau José Vaz Salgado & 204 \\
\hline 19 & Dr. Urbano Sabino Pessoa de Mello & 200 \\
\hline 20 & Francisco Honório Bezerra de Menezes & 199 \\
\hline 21 & Dr. Francisco Joaquim das Chagas & 195 \\
\hline
\end{tabular}



LEGISLATURA DA ASSEMBLEIA PROVINCIAL DE PERNAMBUCO (1835-1836)

\begin{tabular}{|l|l|l|}
\hline 22 & Pe. João Rodrigues de Araújo & 195 \\
\hline 23 & Dr. Francisco de Paula Batista & 192 \\
\hline 24 & Francisco de Carvalho Paes de Andrade & 189 \\
\hline 25 & José Cavalcanti de Albuquerque & 188 \\
\hline 26 & Pe. Cristóvão de Holanda Cavalcanti & 177 \\
\hline 27 & Pe. Joaquim José de Azevedo & 173 \\
\hline 28 & Lourenço Bezerra Cavalcanti de Albuquerque & 170 \\
\hline 29 & Dr. Joaquim Manoel Vieira de Mello & 160 \\
\hline 30 & Luiz Rodrigues Sette & 153 \\
\hline 31 & Francisco Carneiro Machado Rios & 150 \\
\hline 32 & Dr. José Telles de Menezes & 149 \\
\hline 33 & Dr. Joaquim Nunes Machado & 148 \\
\hline 34 & Pe. Antônio da Trindade Antunes Meira & 147 \\
\hline 35 & Bento José da Costa & 147 \\
\hline 36 & Dr. Luiz Francisco de Paula Cavalcanti & 147 \\
\hline
\end{tabular}

\section{Composição política da primeira legislatura}

Da lista final de deputados eleitos pode-se fazer uma análise da composição desta nova instituição. De início chama a atenção a quantidade de padres: eram dez, pouco menos de um terço do número total de deputados. O mais bem votado de todos os candidatos foi um deles, Miguel do Sacramento Lopes Gama, conhecido editor do periódico O Carapuceiro. Ao assumir seu mandato na Assembleia engrossaria a oposição aos liberais moderados, polemizando com uma de suas mais ilustres lideranças, Gervásio Pires.

Três dos irmãos Cavalcanti foram eleitos: Pedro Francisco (futuro Visconde de Camaragibe), Francisco de Paula (futuro Visconde de Suassuna) e Luiz Francisco. ${ }^{\text {xii }}$ Os dois primeiros ficaram entre os três mais bem votados. Deles, Francisco de Paula era o mais experiente na lida política provincial, ocupando por várias vezes o posto de vice-presidente e tendo quase que um lugar cativo no extinto Conselho do Governo.

A força dos Cavalcanti não se limitava à presença dos quatro irmãos. Segundo Nabuco de Araújo, durante a primeira legislatura mais de um terço dos deputados eram aparentados desta família. Da lista acima confirma-se os nomes de Leonardo Bezerra de Siqueira \begin{tabular}{l|l} 
Revista RBBA & Revista Binacional Brasil Argentina
\end{tabular} 
CULTURA POLÍTICA E INSTITUIÇÕES NO BRASIL REGENCIAL: A PRIMEIRA

\section{LEGISLATURA DA ASSEMBLEIA PROVINCIAL DE PERNAMBUCO (1835-1836)}

Cavalcanti e de Lourenço Bezerra Cavalcanti de Albuquerque (ARAÚJO, 1847, p. 4-7). Muito provavelmente também eram parentes os deputados eleitos Joaquim Francisco de Mello Cavalcanti, José Cavalcanti de Albuquerque e Cristóvão de Holanda Cavalcanti.

A nova Assembleia acolheria políticos experientes. Nicolau José Vaz Salgado ficou como suplente de deputado geral para a segunda legislatura (1830-1833), ao lado de figuras como Thomaz Antônio Maciel Monteiro, Caetano Maria Lopes Gama e Bernardo Luiz Ferreira. Dois ex-presidentes da província integrariam seus quadros. Francisco de Carvalho Paes de Andrade estava no cargo quando estouraram a Novembrada, em 1831, e a Abrilada, em 1832. Antes tinha sido eleito juiz de paz da freguesia da Várzea, arrabalde do Recife, em 1829. Era irmão de Manoel de Carvalho Paes de Andrade. O outro ex-presidente era Manoel Zeferino dos Santos, que ocupou a presidência entre novembro de 1832 e setembro de 1833 . Antes de ser nomeado tomou parte do Conselho do Governo entre 1826 e 1832.

Além de Manoel Zeferino, outros ex-Conselheiros também integrariam a Assembleia. Francisco de Paula Cavalcanti de Albuquerque já foi citado. Francisco Joaquim das Chagas foi Conselheiro em 1834, juntamente com Francisco José Correia, que já havia assumido como suplente em 1828. Joaquim Francisco de Mello Cavalcanti, ligado aos Lins de Goiana, também ocupou cadeira no Conselho de 1834, assim como o padre Joaquim José de Azevedo, vigário da Paróquia de Nossa Senhora da Purificação e São Gonçalo de Una e que já tinha sido suplente em 1829. Gervásio Pires Ferreira, velho líder liberal, desempenhou esta função entre 1830 e 1831. O médico José Eustáquio Gomes o foi nos idos de 1826. O desembargador Thomaz Antônio Maciel Monteiro exerceu o cargo em 1826 e entre os anos de 1830 e 1832 . O padre Laurentino Antônio Moreira de Carvalho esteve no Conselho entre 1826 e 1829 e no ano de 1834. Por fim, o padre Virgínio Rodrigues Campelo foi membro do Conselho em 1834.

Lideranças do interior da província também conseguiram se eleger. O padre Cristóvão de Holanda Cavalcanti exercia suas atividades em Limoeiro, onde estava quando ocorreram distúrbios em 1834. Foi um dos que recebeu recomendação do presidente Manoel de Carvalho para evitar distúrbios naquela vila. ${ }^{\text {xiv }}$ Seu nome sugere algum parentesco com o capitão-mor de Pau d'Alho, Cristóvão de Holanda Cavalcanti de Albuquerque. O deputado Francisco Honório Bezerra de Menezes era tenente coronel e juiz de paz eleito em 1829, na capela filial de N. S. do Pilar, no termo de Goiana. O já citado padre Joaquim José de Azevedo era pároco 

LEGISLATURA DA ASSEMBLEIA PROVINCIAL DE PERNAMBUCO (1835-1836)

em Una. Lourenço Bezerra Cavalcanti de Albuquerque foi um respeitado líder político da região de Garanhuns e Cimbres. Na guerra dos Cabanos ocupou o lugar de Comandante Geral das Forças de Garanhuns. O padre Luiz Carlos Coelho da Silva foi eleito vereador de Cimbres em 1829. Tiburtino Pinto de Almeida era Tenente coronel, Chefe da Legião de Guarda Nacional de Santo Antão e vereador daquela vila eleito em 1829.

A Assembleia Provincial também contaria com quatro jovens bacharéis em Direito. Eram eles José Telles de Menezes (juiz de direito da comarca de Santo Antão, nomeado em 1833), Francisco de Paula Batista, Urbano Sabino e Joaquim Manoel Vieira de Mello. Este último seria nomeado juiz de órfãos e municipal da vila de Nazaré ainda em 1835. No futuro ocuparia um lugar de desembargador da Relação de Pernambuco.

Para completar esta análise dos deputados provinciais, outros nomes merecem referência. Os irmãos Antônio e Francisco Carneiro Machado Rios conseguiram converter em votos a sua influência política naqueles conturbados dias. Dois representantes do comércio também foram eleitos: José Ramos de Oliveira e Bento José da Costa. Ambos eram dois dos principais traficantes de escravos das décadas de 1830 e 1840. Já o tenente coronel Firmino Herculano de Moraes Ancora era um militar que atuava na área de engenharia, com uma destacada atuação nas obras públicas.

\section{Os trabalhos da primeira legislatura: 1835}

Com estes deputados, a Assembleia Provincial de Pernambuco deu início a sua primeira legislatura no dia $1^{\circ}$ de abril de 1835 e se estenderia por dois meses, como previa a lei. A maioria de seus deputados era de oposição aos liberais moderados, que desde o início da Regência vinham dominando o poder na província. Transcorridos pouco mais de trinta dias da sua instalação, um certo $O$ Chimango afirmava que já no início a Assembleia foi tomada "pelo espírito de partido". O que os deputados faziam, segundo ele, era oposição por capricho, invasão e usurpação de poderes em favor de seus afilhados, insultos ao presidente e ataques à Câmara Municipal da capital com quem não simpatizavam boa parte de seus membros. Assim, uma coalizão formada pelas facções dos Cavalcanti, ex-restauradores ligados a Araújo Lima (futuro Marques de Olinda) e os liberais exaltados praticamente ditou os rumos tomados pela nova instituição. Esta oposição era liderada pelos irmãos Cavalcanti, especialmente pelo mais velho, Francisco de Paula. Além destes irmãos, outros deputados da oposição serão alvos das críticas dos moderados. O desembargador Thomaz Antônio Maciel Monteiro, 
CULTURA POLÍTICA E INSTITUIÇÕES NO BRASIL REGENCIAL: A PRIMEIRA

\section{LEGISLATURA DA ASSEMBLEIA PROVINCIAL DE PERNAMBUCO (1835-1836)}

primeiro presidente da Assembleia, será um deles. Para o mesmo $O$ Chimango, Maciel Monteiro era "servo humilhíssimo" daquela família. Sua atuação à frente da presidência, ainda segundo ele, era de parcialidade, permitindo que deputados falassem os maiores impropérios contra o ex-presidente Manoel de Carvalho e o então Vicente Camargo. Perguntava, assim, se era desse modo que Maciel Monteiro queria se vingar de seu primo e cunhado Manoel de Carvalho. ${ }^{\mathrm{xv}}$ Outros também receberão destaque, como Miguel do Sacramento Lopes Gama, Francisco de Paula Batista, Félix Peixoto de Brito e Mello e Cipriano José Barata de Almeida. Estes dois últimos entraram posteriormente como suplentes. O Barata, inclusive, será acusado de ter sido beneficiado pela oposição, pois não teria, de acordo com seus adversários, rendimentos para ser elegível. Quanto aos moderados, possuíam como figuras principais os deputados Gervásio Pires, Manoel Zeferino dos Santos e Francisco de Carvalho Paes de Andrade, além do apoio de Urbano Sabino.

A tendência de domínio dos oposicionistas se verificou logo no início dos trabalhos. Na composição da Mesa saiu eleito como presidente o deputado Maciel Monteiro. Outro oposicionista ficou na $2^{\text {a }}$ Secretaria, o Dr. Francisco de Paula Baptista. Um governista ocupou a $1^{\mathrm{a}}$, o padre Laurentino Antônio Moreira de Carvalho.

Uma das novas atribuições da Assembleia Provincial era a da eleição dos vicepresidentes de província. Os nomes escolhidos pelos deputados foram os seguintes: ${ }^{\mathrm{xvi}}$

$1^{\circ}$ vice: Desembargador Thomaz Antônio Maciel Monteiro

$2^{\circ}$ vice: Francisco de Paula Cavalcanti d'Albuquerque

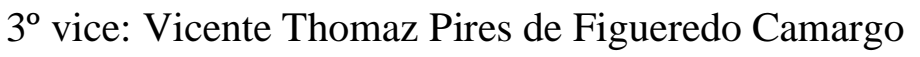

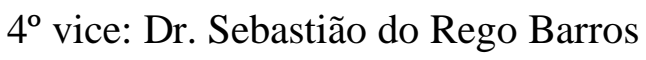

$5^{\circ}$ vice: Dr. Pedro Francisco de Paula Cavalcanti

$6^{\circ}$ vice: Izidro Francisco de Paula Mesquita

Destes seis nomes, pelo menos quatro eram figuras proeminentes da oposição. Havia dois Cavalcanti (Francisco e Pedro), um primo deles (Sebastião do Rego Barros) e o já citado Maciel Monteiro. Apenas o $3^{\circ}$ vice, Vicente Thomaz, era pessoa de confiança dos moderados. Isto significava que, com a saída de Manoel de Carvalho para a Corte, corria-se o sério risco da presidência ficar nas mãos da oposição.

O embate entre deputados moderados e oposicionistas foi acirrado. De cara, os moderados puseram em dúvida a legalidade da posse dos irmãos Machado Rios, líderes dos 

LEGISLATURA DA ASSEMBLEIA PROVINCIAL DE PERNAMBUCO (1835-1836)

liberais exaltados. A alegação era o fato de que ambos estavam sumariados pelo envolvimento nas sedições de janeiro e março daquele ano. O caso foi levado à Comissão de Justiça Criminal, que deu seu parecer na sessão do dia 25 de abril. Segundo os seus integrantes, os deputados Francisco e Antônio Carneiro não poderiam tomar assento na Assembleia por estarem pronunciados. Um parecer em separado foi apresentado afirmando o contrário. No final das contas, prevaleceu o parecer da Comissão.

Como retaliação aos moderados, os irmãos Carneiro enviaram petição à Assembleia questionando o fato de não poderem tomar assento enquanto o deputado Manoel Zeferino, também pronunciado, exercia normalmente o mandato. $\mathrm{O}$ caso foi à mesma Comissão, que deu seu parecer no dia 9 de maio. O problema de Manoel Zeferino era com um desembargador da Relação de Pernambuco, contra o qual tomou uma medida ainda quando era presidente da província. Em contrapartida, o desembargador o acusou e acabou gerando uma pronúncia pelo Supremo Tribunal de Justiça, em fevereiro de 1834. Como Manoel Zeferino na época era deputado geral, o processo não caminhou. No entender da Comissão, ao deixar de ser deputado o processo deveria ser retomado, o que invalidaria até mesmo sua eleição como deputado provincial. Desta forma, e lamentando a decisão, dois dos deputados da Comissão entenderam que Manoel Zeferino deveria perder o mandato. $O$ terceiro integrante, deputado Francisco Joaquim das Chagas, divergiu dos seus colegas e propôs que, antes de qualquer decisão, Manoel Zeferino deveria ser ouvido. Colocada em votação, a proposta do deputado Chagas foi rejeitada pelo plenário. ${ }^{\mathrm{x} \text { ii }}$

A oposição também conseguiu levantar a discussão em torno de uma anistia. Foi apresentado um requerimento solicitando a criação de uma comissão para elaborar uma representação dirigida à Assembleia Geral, onde se pediria a anistia a todos os revoltosos políticos. O seu autor foi o deputado Felix Peixoto de Brito e Mello, um dos suplentes que assumiram mandatos no decorrer dos trabalhos da Assembleia. Pelo seu histórico de vida, Felix Peixoto foi mais um caso de liberal ligado aos exaltados e insatisfeito com os rumos tomados por Manoel de Carvalho Paes de Andrade quando este assumiu a presidência. A comissão redigiu a representação, aprovada no dia 21 de maio após pedido de urgência do próprio Peixoto de Brito. No texto pedia-se a anistia "para todos os crimes políticos, que tem tido lugar nesta Província qualquer que seja a espécie, o grau, e o tempo em que foram cometidos." ${ }^{\text {xviii }}$ 
CULTURA POLÍTICA E INSTITUIÇÕES NO BRASIL REGENCIAL: A PRIMEIRA

\section{LEGISLATURA DA ASSEMBLEIA PROVINCIAL DE PERNAMBUCO (1835-1836)}

A petição foi apresentada à Câmara dos Deputados na sessão do dia 23 de junho, sendo encaminhada para as comissões de Constituição e Justiça Criminal. Nesta mesma sessão o deputado baiano Francisco Ramiro de Assis Coelho apresentou um projeto de resolução de anistia para Pernambuco, pedindo também a urgência na sua discussão. Aprovada a urgência, o pernambucano Holanda Cavalcanti defendeu a necessidade de se tomar medidas neste sentido, aprovando a representação da Assembleia Provincial e atendendo aos votos dos pernambucanos. A pedido do deputado mineiro Baptista Caetano de Almeida, a representação foi lida para o plenário. Nos discursos sobre este tema percebe-se claramente a divisão entre os moderados governistas e a oposição. O pernambucano moderado Antônio Joaquim de Mello votou contra a urgência e pediu para que o seu voto fosse declarado em ata. Já outro moderado pernambucano, o padre Henriques de Rezende, votou a favor da urgência, porém pronunciou-se contrário à anistia. Os deputados Paula Araújo e Vasconcelos discursaram contra ela. Da parte da oposição, os deputados pernambucanos que se manifestaram a favor da urgência e da anistia foram o já citado Holanda Cavalcanti, Antônio Peregrino Maciel Monteiro e Francisco do Rego Barros. Posta em votação, a urgência foi aprovada. $O$ assunto foi retomado nas sessões de 12 e 13 de agosto. Nesta última Maciel Monteiro voltou a discursar a favor da anistia. Encerrada a discussão, o projeto foi aprovado com margem apertada: 42 deputados votaram a favor e 40, contra. Entre os contrários, Henriques de Rezende foi o único que pediu que seu voto constasse em ata. ${ }^{\mathrm{xix}}$

A decisão da Câmara chegou ao Senado na sessão do dia 17 de agosto, ocasião em que foi apresentada proposta estendendo a anistia dada em 19 de junho de 1835 às pessoas envolvidas em crimes políticos em Minas Gerais e Rio de Janeiro também para Pernambuco e Alagoas. Passada em primeira discussão, os maiores debates aconteceram na segunda discussão, que levou quatro sessões para ser findada (dias 26, 27, 28 e 29 de agosto). Quem sustentou a resolução apresentada foi o senador José Saturnino, para quem a Constituição autorizava tal medida quando fosse para o bem da humanidade e do Estado. Fundamentavase, também, na representação da Assembleia Provincial de Pernambuco apresentada à Assembleia Geral. Vergueiro posicionou-se contra, enfatizando o estímulo à impunidade que tais medidas resultavam. Esta mesma linha crítica foi acompanhada pelo senador Borges. $\mathrm{O}$ senador Paula Souza chegou a se posicionar a favor, colocando como condicionante do seu 

LEGISLATURA DA ASSEMBLEIA PROVINCIAL DE PERNAMBUCO (1835-1836)

voto a inclusão de sua emenda estendendo a anistia aos revoltosos de Panelas e Jacuípe que se apresentassem desarmados às autoridades até 40 dias após a publicação da lei. Curiosamente, o senador Manoel de Carvalho Paes de Andrade votou pela anistia e sua extensão aos cabanos. Posta em votação, a resolução foi aprovada, ficando empatados os votos a favor e contra a emenda que estendia o benefício aos cabanos. A aprovação final do Senado ocorreu no dia 4 de setembro, resultando o Decreto $\mathrm{n}^{\circ} 56$, de 6 de outubro de 1835, tornando extensiva às províncias de Pernambuco e Alagoas a anistia concedida às províncias de Minas e Rio de Janeiro pelo Decreto de 19 de junho do mesmo ano (ANAIS, 1978, p. 305, 341-342, 370).

Mas um detalhe na decisão do senado alterou aquilo que os deputados provinciais pernambucanos desejavam. No momento em que repassava a Pernambuco e Alagoas o benefício concedido ao Rio de Janeiro e a Minas, o Decreto $\mathrm{n}^{\circ} 56$ impôs um limite de tempo que existia no Decreto de 19 de junho. Ou seja, o perdão era estendido aos fatos ocorridos até o ano de 1834. ${ }^{\mathrm{xx}}$ Foram beneficiados os restauradores da Abrilada e os envolvidos na Guerra dos Cabanos. Já os Carneiristas de janeiro e março de 1835 ficaram de fora. Foi este o entendimento do juiz de direito e chefe de polícia do Recife, Nunes Machado. Isso lhe valeu críticas de Nabuco de Araújo, que por meio do seu periódico O Aristarco forçava a interpretação de que a anistia alcançaria a todos. Os principais líderes das Carneiradas, os irmãos Antônio e Francisco Machado Rios, acabaram passando pelo tribunal do júri, o que não significaria grandes dificuldades para eles, visto alcançarem facilmente a absolvição.

Durante as reuniões da Assembleia naquele mês de abril, o deputado mais ativo foi o ícone das lutas liberais durante a independência em Pernambuco, Gervásio Pires Ferreira. Principal nome entre os deputados liberais moderados, apresentou uma série de projetos ligados a diferentes temas, que iam de questões ligadas ao comércio na província até a obras de melhoramento. O mais polêmico deles foi o que propunha medidas para normatizar o meio circulante e tentar acabar com os problemas gerados pela fabricação de moedas de cobre falsas. Seus adversários, dentre os quais se destacava o padre Miguel do Sacramento Lopes Gama, criticavam sua iniciativa dizendo que tal assunto era da exclusiva alçada da Assembleia Geral.

A atuação de Gervásio Pires como deputado provincial foi duramente criticada pelo padre Lopes Gama. Por meio de periódicos os dois lançaram mão de uma intensa troca de acusações e de ofensas. O padre dizia que o problema do seu adversário foi o "orgulho incomportável". Logo eleito, Gervásio pensou ser “o oráculo de Dódona na nova 
CULTURA POLÍTICA E INSTITUIÇÕES NO BRASIL REGENCIAL: A PRIMEIRA

\section{LEGISLATURA DA ASSEMBLEIA PROVINCIAL DE PERNAMBUCO (1835-1836)}

Assembleia”, sendo os demais deputados meros admiradores e aprovadores de sua opinião. “...e em consequência deu-se à tarefa de afogar a Assembleia em um dilúvio de Projetos, onde aparecem coisas boas de mistura com outras inexequíveis, outras já criadas por Leis, e outras monstruosamente concebidas..." Em resposta, Gervásio Pires insinuou que as críticas a seus projetos e a não aprovação de alguns deles estava relacionada com o fato de se oporem a interesses particulares de alguns deputados, de parentes e apadrinhados destes. ${ }^{\mathrm{xxi}}$

No final das contas, o projeto de Gervásio Pires sobre moedas de cobre não foi aprovado e acabou sendo a gota d'água para que ele decidisse renunciar ao seu mandato. $\mathrm{Na}$ sessão do dia 30 de abril, ele enviou ao $2^{\circ}$ Secretário um ofício onde se despedia da Assembleia alegando doença e por seus trabalhos não corresponderem aos seus desejos. A má fase de Gervásio Pires na lida política pernambucana naqueles dias era um indicador das dificuldades que o grupo dos liberais moderados viviam. Já haviam perdido Manoel Zeferino e agora deixava o campo de batalha o seu principal nome na Assembleia Provincial. Isto só piorou a vida dos moderados naquela casa. A oposição consolidou suas ações, restando aos moderados criticar os rumos tomados pela Assembleia. Um mês depois dos inícios de seus trabalhos, ela era assunto de um artigo do Velho Pernambucano, porta-voz dos moderados na imprensa. Para o redator, passaram-se trinta dias e nenhuma lei havia saído do seu recinto. Ela por muitas vezes estava exorbitando das suas atribuições, avançando sobre aquelas que eram exclusivas da Assembleia Geral e do Poder Executivo. Dava ordens para que o presidente da província cassasse diplomas de empregados da Fazenda, da esfera do Poder Central, e ordenava que fossem nomeadas pessoas de acordo com a vontade dos deputados. Chegava a acontecer, segundo ainda o artigo, a posse de suplentes sem diploma e sem o número de votos necessários. $^{\text {xxii }}$ A lamúria dos moderados contra a Assembleia Provincial estava só começando, pois o domínio da oposição, que pouco mais tarde se tornaria governo, se prolongaria por um bom tempo. 

LEGISLATURA DA ASSEMBLEIA PROVINCIAL DE PERNAMBUCO (1835-1836)

\section{A Lei de Prefeitos de 1836}

De todas as medidas tomadas pela Assembleia Provincial de Pernambuco durante a sua primeira legislatura, a que teve maior impacto na luta política local e cujos desdobramentos se revelaram mais prolongados foi a aprovação da chamada Lei de Prefeitos. Ela aconteceu no início de 1836, quando novos ares começavam a surgir na política nacional e local. A eleição e posse do novo regente, o padre Feijó, resultou em um racha na corrente liberal moderada da corte que controlava o poder desde a abdicação de Pedro I, em 1831. Começava a surgir um movimento de crítica às medidas descentralizadoras que até então tinham sido tomadas, em especial ao Código de Processo Criminal de 1832 e todo o poder que o mesmo conferiu à figura do juiz de paz. Era o início do movimento que ficaria conhecido como Regresso, e que em Pernambuco foi encabeçado pela oligarquia dos Cavalcanti e seus aliados. (CAVALCANTI JUNIOR, 20019).

Em 1836 a configuração política em Pernambuco já não era a mesma do ano anterior. A presidência da província saiu das mãos dos liberais moderados locais e ficou com a oligarquia dos Cavalcanti. Um dos irmãos, Francisco de Paula Cavalcanti de Albuquerque, agora ocupava o cargo. Os trabalhos na Assembleia Provincial tiveram início em 14 de março, convocada extraordinariamente pelo presidente da província. $\mathrm{O}$ ato foi censurado pelos moderados, agora na oposição, que não viam razão para isto, já que faltavam apenas quinze dias para o início da sessão ordinária. Na sua fala de abertura dos trabalhos, o presidente justificou a convocação com base em dois motivos. O primeiro era rediscutir a lei que fixou a receita provincial de 1835/36. Antes a província tinha a possibilidade de fazer uso da renda geral a partir de $1^{\circ}$ de julho para cobrir as despesas quando a renda provincial não bastasse. Com as mudanças promovidas pelo Ato Adicional isto não mais poderia ser feito. $\mathrm{O}$ segundo dizia respeito à necessidade de se criar uma repartição onde fosse feita a fiscalização, escrituração e contabilidade de todas as rendas provinciais. ${ }^{\text {xiii }}$ Estes assuntos acabariam sendo ofuscados pelo projeto dos prefeitos, com teor muito mais polêmico e de maior impacto na luta política que então se desenrolava no Império e especificamente na província. A convocação extraordinária pode ser entendida como uma das estratégias de viabilização deste projeto. O risco para o grupo regressista ao se restringir apenas à sessão ordinária era o das discussões se prolongarem e alguns dos deputados aliados terem que abandonar prematuramente a Assembleia para irem assumir seus mandatos na Câmara. A convocação 
CULTURA POLÍTICA E INSTITUIÇÕES NO BRASIL REGENCIAL: A PRIMEIRA

\section{LEGISLATURA DA ASSEMBLEIA PROVINCIAL DE PERNAMBUCO (1835-1836)}

extraordinária representava a garantia de tempo maior para a tramitação do projeto e sua aprovação ainda em 1836.

A composição da Assembleia de 1835 que favorecia uma aliança entre restauradores, Cavalcanti e liberais exaltados contra os liberais moderados ainda estava de pé no início dos trabalhos da sessão extraordinária. Pelo menos momentaneamente. $\mathrm{Na} 1^{\mathrm{a}}$ sessão preparatória houve uma mobilização por parte dos deputados Luiz Cavalcanti, Manoel Joaquim Vieira de Mello e Firmino Herculano de Moraes Âncora para que os irmãos Francisco e Antônio Carneiro Machado Rios fossem convocados. No ano anterior, por se encontrarem pronunciados, não participaram dos trabalhos legislativos. Como foram absolvidos pelo júri no dia 5 de março, não havia mais empecilho para assumirem seus mandatos. Outros deputados foram convocados como suplentes: Dr. Francisco Xavier Pereira de Brito, Dr. José Eustáquio Gomes, Dr. Antônio Peregrino Maciel Monteiro, Dr. Felix Peixoto de Brito e Mello, padre Manoel da Fonseca e Silva e Dr. Francisco do Rego Barros. ${ }^{\text {xxiv }}$

Estas novidades beneficiaram as bancadas dos liberais exaltados e a dos regressistas, formada pela aliança entre antigos restauradores e os Cavalcanti. A primeira ganhou o reforço dos irmãos Machado Rios. Felix Peixoto já havia atuado no ano anterior. A segunda ganhou dois nomes de peso: o médico Maciel Monteiro e Francisco do Rego Barros, futuro Barão e Conde da Boa Vista. Homens bem articulados e já experientes na lida política, Rego Barros era primo dos Cavalcanti, ligado a Araújo Lima e estava em seu segundo mandato como deputado geral. Maciel Monteiro era aliado de primeira hora dos Cavalcanti e exercia seu primeiro mandato na Câmara. Ambos estavam bem articulados com as discussões em torno das ideias regressistas que começaram a florescer durante os trabalhos da Assembleia Geral no ano anterior.

Com esta composição de forças os Cavalcanti se sentiram à vontade para apresentar uma proposta de reforma da polícia e outros objetos. Era o projeto de lei $\mathrm{n}^{\mathrm{o}} 1$, de autoria do deputado Luiz Francisco de Paula Cavalcanti de Albuquerque, apresentado na $3^{\text {a }}$ sessão extraordinária, dois dias após a abertura dos trabalhos. As circunstâncias e a envergadura do projeto indicam que a bancada regressista já tinha um plano formulado quando a sessão extraordinária da Assembleia teve início. Não se fazia um texto daquele da noite para o dia. $\mathrm{O}$ objetivo era claro: reverter na província parte das reformas liberais até então implementadas e 

LEGISLATURA DA ASSEMBLEIA PROVINCIAL DE PERNAMBUCO (1835-1836)

trazer para as mãos do governo as nomeações de cargos vitais para o controle social e o jogo político-eleitoral.

Luiz Cavalcanti, que vale lembrar também era Desembargador da Relação, propunha mudanças significativas na estrutura judiciária da província. Sua principal vítima era a figura do juiz de paz, que perderia o poder de polícia a ele concedido pelo Código de Processo de 1832, voltando a se limitar à conciliação. Propunha mudanças na organização e funcionamento dos júris, com as listas de jurados passando a serem organizadas pelo prefeito e a qualificação para ser jurado deixaria de ser a de eleitor (200 mil réis) e passaria a ser de 300 mil réis provenientes da agricultura, criação ou bens de raiz. De outros ramos, o valor saltaria para 600 mil réis. Previa-se a extinção dos cargos de juiz municipal, de órfãos e inspetores de quarteirão. Não mais existiria um promotor por termo, mas um para cada comarca. A nomeação deixaria de ser por meio de lista tríplice das Câmaras Municipais e passaria a ser feita diretamente pelo presidente da província, a quem caberia também a remoção quando considerasse a bem do serviço público. O promotor acumularia questões crimes e cíveis, relativas a heranças e administração de bens de órfãos. Seria ele o substituto do prefeito em suas ausências, não podendo acumular as duas funções.

$\mathrm{Na}$ Guarda Nacional o projeto extinguia a eleição de oficiais. Os oficiais superiores dos Batalhões passariam a ser nomeados pelo presidente da província na forma em que eram os Chefes de Legiões. Os oficiais subalternos o seriam pelo prefeito da comarca, enquanto a nomeação dos oficiais inferiores ficaria a cargo dos Comandantes do Corpo. A responsabilidade pela qualificação para ser Guarda nacional seria do comandante do respectivo corpo com recurso ao prefeito da comarca. Ficavam abolidos os Conselho de Qualificação e o Júri de Revista. A Guarda Nacional deveria ser subordinada ao prefeito.

O projeto de prefeitos logo se tornou alvo de ataques e pesadas críticas na imprensa por parte dos liberais moderados. O seu veículo oficial era o periódico Constituição e Pedro $2^{\circ}$, que substituiu O Velho Pernambucano e começou a circular no dia 10 de março de 1836. Para a oposição moderada o projeto significava uma tentativa de golpe contra a Constituição e o Ato Adicional. Chegaram a batizá-lo de "projeto de regresso Holandez", em alusão a Holanda Cavalcanti e à influência de sua família sobre as articulações para sua aprovação.

Como qualquer projeto, o de $\mathrm{n}^{\mathrm{o}} 1$ deveria passar por três discussões. A primeira consistiria em debater as vantagens e inconvenientes da proposta em geral. Na segunda seriam debatidos cada artigo individualmente, podendo ser apresentas emendas a cada um deles. $\mathrm{Na}$

\begin{tabular}{l|l} 
Revista RBBA & Revista Binacional Brasil Argentina
\end{tabular} 
CULTURA POLÍTICA E INSTITUIÇÕES NO BRASIL REGENCIAL: A PRIMEIRA

\section{LEGISLATURA DA ASSEMBLEIA PROVINCIAL DE PERNAMBUCO (1835-1836)}

terceira e última seriam retomadas as questões e os argumentos levantados nas duas discussões anteriores. O que chama a atenção na tramitação desse projeto é a sua rapidez. Com a ajuda da presidência da Assembleia, nas mãos de Thomaz Antônio Maciel Monteiro, os prazos seguidos foram sempre os mínimos exigidos por lei. O resultado foi que o projeto levou apenas vinte e três dias para ser discutido e finalmente aprovado.

Uma vez que o projeto mexia com pontos caros aos princípios da descentralização promovida até aquele momento da Regência, os liberais moderados tiveram um reforço na luta contra a sua tramitação dado pelos liberais exaltados. Esta oposição travou duras disputas nas sessões, mas tentou também angariar apoio popular. Em 8 de abril, quando começava a terceira discussão, a oposição organizou uma petição contra o projeto de Luiz Cavalcanti. No Diário de Pernambuco do dia anterior saiu um aviso particular convocando os "verdadeiros patriotas e amigos da liberdade" a comparecerem na manhã do dia 8, pelas 9h, na Igreja de São Francisco, desarmados, para assinarem um requerimento à Assembleia Provincial em nome do povo. Dizia que o organizador da reunião era o juiz de paz do distrito, no caso o $1^{\circ}$ de Santo Antônio, José Tavares Gomes da Fonseca. O objetivo era "requerer contra o monstruoso Projeto que nada menos importa do que escravizar esta Província com a criação de Prefeitos, e abolição das Autoridades Legitimamente criadas pela Assembleia Legislativa do Império." Na mesma edição o juiz de paz José Tavares, sabendo que a nota seria publicada, escreveu negando ser ele o organizador daquela reunião. ${ }^{\mathrm{xxv}}$

Uma reunião daquele tipo em meio ao clima pesado da disputa política levou preocupação às autoridades. No dia 8 o chefe de polícia, juiz Joaquim Nunes Machado, encaminhou um ofício ao juiz de paz José Tavares ordenando que tomasse as providências no sentido de não permitir que houvesse excessos ou ameaça à tranquilidade pública na reunião. Precavido, o juiz de paz já estava no Convento de São Francisco ao receber o ofício, juntamente com os seus inspetores de quarteirão, escrivão e meirinho. O próprio chefe de polícia depois passou por lá. O governo provincial foi mais além. Pela manhã mandou postar tropas da companhia montada e de destacamentos do Corpo de Polícia no campo do Palácio Velho e no largo da Igreja do Hospital do Paraíso, cercando assim o lugar do ajuntamento. Segundo os moderados, parecia até que a cidade estava ameaçada de revolução. ${ }^{\text {xxi }}$

Essa pressão policial e o recrutamento que vinha sendo feito desde o dia anterior acabaram afugentando possíveis apoiadores da petição. Nabuco de Araújo chamou aquela 

LEGISLATURA DA ASSEMBLEIA PROVINCIAL DE PERNAMBUCO (1835-1836)

reunião de "o Triunfo dos Proletários" e "assembleia de vadios". Em tom satírico, disse que os franciscanos deixaram os organizadores da petição do lado de fora, questionando se a frente do convento havia sido transformada em um novo Campo dos Canecas. Tentaram de tudo para convencer os que por ali passavam para assinarem o documento, mas somente quarenta que já haviam dado a palavra compareceram. Os "proletários patriotas" se trancaram em suas casas temerosos de serem recrutados. ${ }^{\text {xvii }}$

Ainda de acordo com o texto de Nabuco, foram seis os indivíduos que estiveram no Convento dos Franciscanos colhendo assinaturas: Vulcão (João de Barros Falcão de Albuquerque Maranhão, redator do Republicano Federativo), Tonto do Nobre (Antônio José Fernandes Nobre), Maluco Pires (Domingos Pires Ferreira, parente de Gervásio Pires), Bússola da Liberdade (o padre João Barbosa Cordeiro, editor do jornal com o mesmo nome), Pouca Fortuna (padre Ignácio de Almeida Fortuna) e o Miserável Filisbino (não identificado). Pela composição partidária deste grupo, podemos afirmar que muito provavelmente a iniciativa da representação partiu dos liberais exaltados. Nabuco de Araújo apontou suas críticas mais ferrenhas aos padres Cordeiro e Fortuna. Ambos eram deputados gerais por Pernambuco e tinham presenciado no ano anterior o surgimento das ideias regressistas na Assembleia Geral. As poucas assinaturas da representação mostravam, segundo Nabuco de Araújo, que eles não tinham influência alguma. Sua recomendação a estes padres era para que deixassem a política e se dedicassem ao breviário. Um, que cuide de defender sua reputação de tudo o que se diz até aquele dia a seu respeito (Barbosa Cordeiro era acusado constantemente pelos seus adversários de participar do roubo da carga de um brigue inglês naufragado próximo a Goiana). O outro, Ignácio Fortuna, por ser já velho não lhe cabiam bem certas ideias, "que quando muito teriam lugar em uma criança ignorante e sem experiência".xxviii

A petição teve exatamente quarenta e seis assinaturas. ${ }^{\text {xxix }}$ Eram poucas para um documento que tinha por objetivo pressionar os deputados a não aprovarem o projeto de Luiz Cavalcanti. Além dos cinco anteriormente citados, outros personagens podem ser identificados. Firmino Theotonio da Câmara era da Várzea, onde conseguiria ser eleitor suplente nas eleições de 1836. Simão Cavalcanti Macambira era comerciante, sócio na Casa de Negócios de Macambira \& Comp., juntamente com Antônio de Siqueira Cavalcanti, Leonardo Bezerra de Siqueira Cavalcanti e Antônio Luiz Ribeiro de Brito. Gonçalo Francisco Martins tinha sido juiz de paz do $5^{\circ}$ distrito das Cinco Pontas durante as Carneiradas. Havia 
CULTURA POLÍTICA E INSTITUIÇÕES NO BRASIL REGENCIAL: A PRIMEIRA

\section{LEGISLATURA DA ASSEMBLEIA PROVINCIAL DE PERNAMBUCO (1835-1836)}

alguns peticionários que se envolveram com a sedição dos irmãos Carneiro. Antônio de Barros Falcão de Albuquerque Maranhão chegou a ser preso durante a presidência de Manoel de Carvalho Paes de Andrade. Não fora a primeira vez: em 1824 também foi encarcerado por sustentar o governo do mesmo que o mandou prender em 1835. O alferes João Baptista de Souza foi suspenso, mas acabou absolvido. Seria eleitor em 1836 da freguesia da Boa Vista, reduto eleitoral de Antônio Carneiro Machado Rios. Se os irmãos Carneiro mais famosos não assinaram a petição, um de seus irmãos o fez. Foi Joaquim Carneiro Machado Rios, também envolvido com as Carneiradas e eleitor da freguesia da Boa Vista.

O conteúdo da petição denunciava a criação de um novo e poderoso partido na província. Ele surgiu a partir do retorno de alguns deputados gerais pernambucanos da capital do Império, que inclusive também eram deputados provinciais. Seus órgãos oficiais na imprensa, O Aristarco e Diário de Pernambuco, disseminavam ideias subversivas contra os direitos civis e políticos dos cidadãos brasileiros e até contra o então Regente do Império. $\mathrm{O}$ projeto apresentado pelo deputado Luiz Cavalcanti era fruto das ideias desse partido, cujo objetivo consistia em destruir sorrateiramente as liberdades civis e políticas garantidas pela Constituição. A aprovação deste projeto traria a desordem para a província, pois ele destruiria a independência dos poderes políticos ao conceder atribuições judiciais aos prefeitos, que são na verdade agentes do Poder Executivo. Os peticionários, diziam eles, só tinham aos deputados para recorrer, pois o presidente da província era irmão do autor do projeto e não tinha como não ser parte do plano de sua aprovação.

No dia 9 de abril o documento foi lido e encaminhado para a comissão de petições, formada pelos deputados José Teles de Menezes, Félix Peixoto e Leonardo Bezerra. Na sessão seguinte o parecer foi apresentado pelo deputado Peixoto. O seu teor não consta na ata, mas com aquela composição dificilmente a comissão lhe daria algum valor. Ele seria fatalmente aprovado pela maioria, só não acontecendo porque a sua votação foi adiada devido à intervenção do deputado Francisco Xavier Pereira de Brito, opositor do projeto. O mesmo deputado tentou uma manobra para suspender a discussão do projeto e só retomá-la após a votação do parecer da petição. Acabou sendo voto vencido, a discussão continuou e o projeto foi aprovado naquela mesma sessão. ${ }^{\mathrm{xx}}$ Em um tempo recorde, menos de 30 dias, o projeto $\mathrm{n}^{\mathrm{o}}$ 1 tramitou e, com algumas modificações, virou lei no dia 14 de abril. Era um sinal da força política dos regressistas na província. 
A instalação da Assembleia Provincial em Pernambuco foi, portanto, resultado e retrato das mudanças que a Regência vinha experimentando desde o seu início. Era a consolidação de princípios que defendiam uma maior descentralização do poder no Império. Curiosamente, no caso de Pernambuco, este instrumento descentralizador foi utilizado por aqueles que defendiam um retorno a uma maior centralização. Com a aprovação da Lei de Prefeitos, o presidente da província passaria a ter poder de nomeação para diversos cargos na estrutura jurídica e policial local. Quem estivesse com a presidência em mãos teria o controle do poder político provincial. Tal modelo era justamente o que defendia o movimento regressista e que começaria a colocar em marcha a nível nacional com a sua chegada ao poder através do pernambucano Araújo Lima, futuro sucessor do padre Feijó no cargo de Regente do Império.

\section{Referências}

Anais do Senado do Império do Brasil - Terceira Legislatura - Sessões de maio a outubro de 1835. Brasília: Senado Federal, 1978.

ARAÚJO, J. T. N. de. Justa apreciação do predomínio do Partido Praieiro ou história da dominação da Praia. Pernambuco: Typografia União, 1847.

BASILE, M. O laboratório da Nação: a era regencial (1831 - 1840). In: GRINBERG, Keila e SALLES, Ricardo (org.). O Brasil Imperial, volume II: 1831 - 1870. Rio de Janeiro: Civilização Brasileira, 2009.

CARVAlHO, J. M. de. Pontos e bordados. Escritos de história política. Belo Horizonte: Editora da UFMG, 2005.

CAVALCANTI JUNIOR, M. N. Um passo atrás: o movimento regressista na província de Pernambuco (1835-1836). Anais do $30^{\circ}$ Simpósio Nacional de História - História e o futuro da educação no Brasil / organizador Márcio Ananias Ferreira Vilela. Recife: Associação Nacional de História - ANPUH-Brasil, 2019.

DOLHNIKOFF, M. O Pacto Imperial: origens do federalismo no Brasil. São Paulo: Globo, 2005. 
CULTURA POLÍTICA E INSTITUIÇÕES NO BRASIL REGENCIAL: A PRIMEIRA

\section{LEGISLATURA DA ASSEMBLEIA PROVINCIAL DE PERNAMBUCO (1835-1836)}

\section{Notas}

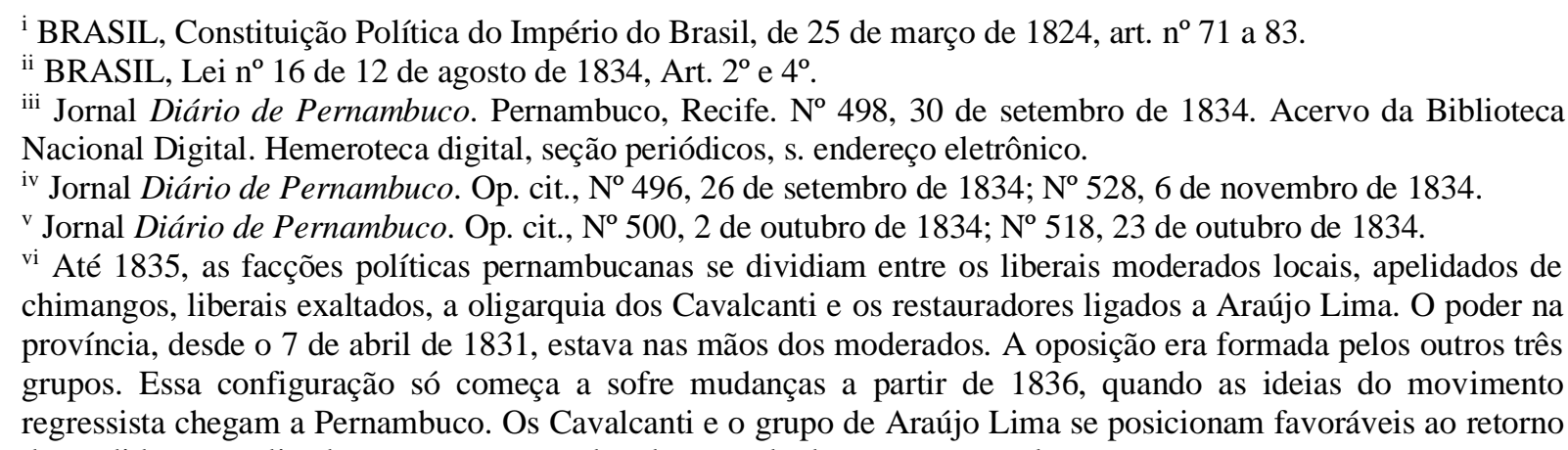
de medidas centralizadoras, enquanto moderados e exaltados se opõem a elas.

vii Manoel de Carvalho Paes de Andrade, presidente da província de Pernambuco durante a Confederação do Equador de 1824, havia voltado do exílio após a abdicação de Pedro I. Bastante popular, era tido pelo grupo dos liberais exaltados locais como um dos seus. Assumiu a presidência da província pela segunda vez em janeiro de 1834, em meio a uma grave crise política. Desentendeu-se com os exaltados e destes sofreu grande oposição, chegando a uma tentativa de deposição à força que ficou conhecida como Carneiradas. Sobre este assunto, ver CAVALCANTI JUNIOR, Manoel Nunes. Revisitando as Carneiradas: os irmãos Machado Rios e as disputas políticas em Pernambuco (1834-1835). Clio: Revista de Pesquisa Histórica. Revista do Programa de PósGraduação da UFPE, Recife, $n^{\circ}$ 33, vol. 1, 2015.

viii Jornal Escudo da Monarchia Constitucional. Recife, Pernambuco. № 8, 7 de outubro de 1835. Acervo do Arquivo Público Estadual Jordão Emereciano (APEJE), Hemeroteca.

ix Jornal $O$ Velho Pernambucano. Recife, Pernambuco. $\mathrm{N}^{\circ} 33,14$ de setembro de 1835. Acervo do APEJE, Hemeroteca.

${ }^{x}$ Jornal Diário de Pernambuco. Op. cit., No 19, 25 de fevereiro de 1835; No 21, 27 de fevereiro de 1835.

xi Jornal Diário de Pernambuco. Op. cit., № 45, 30 de março de 1835. Além dos vereadores já citados, estavam presentes Thomaz José da Silva Gusmão, José Bento da Costa, Antônio Luiz de Souza, Antônio João da Ressurreição e Silva e um certo Cavalcanti, não identificado.

xii Jornal Diário de Pernambuco. Op. cit., № 20, 26 de fevereiro de 1835.

xiii Os irmãos Cavalcanti eram: Manoel Francisco de Paula Cavalcanti de Albuquerque (Barão de Muribeca), Luís Francisco de Paula Cavalcanti de Albuquerque, Antônio Francisco de Paula de Holanda Cavalcanti de Albuquerque (Visconde de Albuquerque), Francisco de Paula Cavalcanti de Albuquerque (Visconde de Suassuna) e Pedro Francisco de Paula Cavalcanti e Albuquerque (Visconde de Camarajibe). Os três últimos foram senadores por Pernambuco.

xiv Jornal Diário de Pernambuco. Op. cit., № 540, 20 de novembro de 1834.

${ }^{x v}$ Jornal $O$ Velho Pernambucano. Op. cit, $\mathrm{N}^{\circ} 13,13$ de maio de 1835 . A presidência da província mudou de mãos logo no início dos trabalhos da Assembleia. Manoel de Carvalho foi para a corte assumir sua cadeira no Senado e foi substituído por Vicente Thomaz Pires de Figueredo Camargo.

xvi Jornal Diário de Pernambuco. Op. cit., N N $^{\circ} 2,7$ de abril de 1835.

xvii Jornal Diário de Pernambuco. Op. cit., № 74, 5 de maio de 1835; № 91, 27 de maio de 1835; № 88, 23 de maio de 1835.

xviii Jornal Diário de Pernambuco. Op. cit., № 79, 13 de maio de 1835; № 97, 4 de junho de 1835; No 114, 2 de julho de 1835.

xix Annaes do Parlamento Brasileiro - Câmara dos Srs. Deputados - Segundo Ano da Terceira Legislatura Sessão de 1835. Tomo I. Rio de Janeiro: Typographia de Viúva Pinto \& Filhos, 1887. p. 190,199-201; Tomo II. p. 165-166. Acervo da Biblioteca Nacional Digital. Hemeroteca digital, seção periódicos, s. endereço eletrônico.

xx BRASIL, Decreto ${ }^{\circ}$ 6, de 19 de junho de 1835 .

xxi Jornal Diário de Pernambuco. Op. cit., № 85, 20 de maio de 1835; № 91, 27 de maio de 1835.

xxii Jornal $O$ Velho Pernambucano. Op. cit, № 13, 13 de maio de 1835.

xxiii Jornal Diário de Pernambuco. Op. cit., N ${ }^{\circ}$ 60, 15 de março de 1836.

xxiv Jornal Diário de Pernambuco. Op. cit., No 61, 16 de março de 1836.

xxv Jornal Diário de Pernambuco. Op. cit., No 76B, 9 de abril de 1836. 


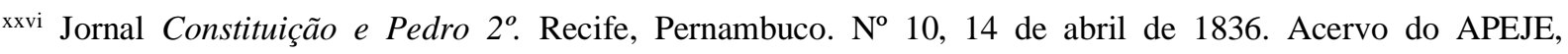
Hemeroteca.

xxvii Jornal A Ponte da Boa Vista. Recife, Pernambuco. $\mathrm{N}^{\mathrm{o}}$ 2, 13 de abril de 1836. Acervo do APEJE, Hemeroteca.

xxviii Idem, ibdem.

xxix Arquivo da Assembleia Legislativa de Pernambuco, Petição redigida contra o Projeto de Lei do Deputado Luiz Francisco de Paula Cavalcanti enviada aos deputados da Assembleia Provincial de Pernambuco. Datada de 8 de abril de 1836. Fundo Petição: Caixa 115, doc. 044/115P.

xxx Jornal Diário de Pernambuco. Op. cit., № 84, 18 de abril de 1836.

Sobre o autor

Manoel Nunes Cavalcanti Junior é graduado (Licenciatura e Bacharelado) em História pela Universidade Federal de Pernambuco, sendo Mestre e Doutor em História pela mesma instituição. Atualmente é Professor Titular de História do Instituto Federal da Bahia/Campus de Vitória da Conquista. Suas pesquisas dizem respeito, principalmente, às relações de poder e cultura política no Brasil durante o período Regencial e início do Segundo Reinado.

Endereço eletrônico: manoel_46@hotmail.com 